\title{
Aspergillus niger Secretes Citrate to Increase Iron Bioavailability
}

\author{
Dorett I. Odoni ${ }^{1}$, Merlijn P. van Gaal ${ }^{1,2}$, Tom Schonewille ${ }^{1}$, Juan A. Tamayo-Ramos ${ }^{1}$, \\ Vitor A. P. Martins dos Santos ${ }^{1,3}$, Maria Suarez-Diez ${ }^{1}$ and Peter J. Schaap ${ }^{1 *}$
}

${ }^{1}$ Laboratory of System and Synthetic Biology, Wageningen University \& Research, Wageningen, Netherlands, ${ }^{2}$ Laboratory of Microbiology, Wageningen University \& Research, Wageningen, Netherlands, ${ }^{3}$ LifeGlimmer GmBH, Berlin, Germany

\section{OPEN ACCESS}

Edited by:

Charley Christian Staats, Universidade Federal do Rio Grande do Sul, Brazil

Reviewed by:

Sean Doyle,

Maynooth University, Ireland Olaf Kniemeyer, Leibniz Institute for Natural Product Research and Infection Biology Hans-Knoell-Institute (HKI), Germany

*Correspondence:

Peter J. Schaap peter.schaap@wur.n

Specialty section: This article was submitted to

Fungi and Their Interactions,

a section of the journal

Frontiers in Microbiology

Received: 15 May 2017

Accepted: 13 July 2017

Published: 02 August 2017

Citation:

Odoni DI, van Gaal MP, Schonewille T, Tamayo-Ramos JA, Martins dos Santos VAP, Suarez-Diez M and Schaap PJ (2017) Aspergillus niger Secretes Citrate to Increase Iron Bioavailability

Front. Microbiol. 8:1424. doi: 10.3389/fmicb.2017.01424
Aspergillus niger has an innate ability to secrete various organic acids, including citrate. The conditions required for $A$. niger citrate overproduction are well described, but the physiological reasons underlying extracellular citrate accumulation are not yet fully understood. One of the less understood culture conditions is the requirement of growth-limiting iron concentrations. While this has been attributed to iron-dependent citrate metabolizing enzymes, this straightforward relationship does not always hold true. Here, we show that an increase in citrate secretion under iron limited conditions is a physiological response consistent with a role of citrate as $A$. niger iron siderophore. We found that $A$. niger citrate secretion increases with decreasing amounts of iron added to the culture medium and, in contrast to previous findings, this response is independent of the nitrogen source. Differential transcriptomics analyses of the two $A$. niger mutants NW305 (gluconate non-producer) and NW186 (gluconate and oxalate non-producer) revealed up-regulation of the citrate biosynthesis gene citA under iron limited conditions compared to iron replete conditions. In addition, we show that $A$. niger can utilize Fe(III) citrate as iron source. Finally, we discuss our findings in the general context of the $\mathrm{pH}$-dependency of $A$. niger organic acid production, offering an explanation, besides competition, for why $A$. niger organic acid production is a sequential process influenced by the external $\mathrm{pH}$ of the culture medium.

Keywords: Aspergillus niger, citrate secretion, iron homeostasis, siderophores, metabolic overflow

\section{INTRODUCTION}

The filamentous fungus Aspergillus niger has an innate ability to secrete organic acids in high quantities, and is essential as a biotechnological citrate producer (Schuster et al., 2002). On glucose as carbon source, wild type $A$. niger secretes gluconate and oxalate as well as citrate. To inhibit by-production of gluconate and oxalate, $A$. niger citrate production requires $\mathrm{pH} \leq 2.5$ and the absence of manganese $\left(\mathrm{Mn}^{2+}\right)$ ions, thereby enforcing overproduction of citrate instead (Currie, 1917; Kubicek and Röhr, 1977; Ruijter et al., 1999). Further production conditions that have been reported to influence external citrate accumulation are, amongst others, the choice and concentrations of the carbon and nitrogen sources, and the concentrations of trace elements in the culture medium (Karaffa and Kubicek, 2003).

Although suggested to be the basis of industrial A. niger citrate production (Neilands, 1981), the physiological reason underlying the particular requirement of suboptimal iron concentrations to prompt increased A. niger citrate secretion is not yet fully understood. Iron $(\mathrm{Fe})$ is essential for virtually all biological systems. In aerobic environments, ferrous ( $\mathrm{Fe}(\mathrm{II})$ ) iron is oxidized to ferric 
(Fe(III)) oxyhydroxide polymers (FeOOH), which are stable and have low solubility in aqueous environments, especially at neutral $\mathrm{pH}$ (Guerinot and Yi, 1994). Thus, although omnipresent, iron is often biologically unavailable. Iron excess, on the other hand, can be harmful due to the ability of Fe(II) to catalyze the formation of cell-damaging reactive oxygen species, and microbes have thus developed complex systems for tight control over iron uptake and intracellular storage (Haas, 2014).

In fungi, there are four known systems of iron uptake: (i) lowaffinity (ferrous) iron uptake, (ii) heme uptake and degradation, (iii) reductive iron assimilation (RIA), and (iv) siderophore mediated (ferric) iron uptake (which, in some cases, involves RIA) (Haas, 2014). Low affinity ferrous iron uptake is less relevant under iron limited conditions, and the A. niger heme uptake system has been recently studied (Franken et al., 2014). Iron siderophores are low molecular weight molecules that are secreted to scavenge (ferric) iron from the environment and make it available to the microbe. This can be either by reduction of the siderophore bound Fe(III) to more soluble Fe(II), which is then imported separately from the siderophore (i.e., RIA), or by uptake of the whole iron-siderophore complex (Neilands, 1995).

Iron uptake and siderophore biosynthesis in Aspergilli has been found to be under the control of the transcription factors SreA and HapX, which are interconnected in a negative feedback loop (Hortschansky et al., 2007; Schrettl et al., 2008). Under conditions of iron excess, SreA represses HapX as well as the high-affinity iron uptake system and iron siderophore biosynthesis, thereby avoiding the uptake of toxic amounts of iron (Schrettl et al., 2008). Under iron limited conditions, HapX is derepressed, and, in turn, HapX represses SreA as well as iron-dependent pathways (Hortschansky et al., 2007).

With the exception of some budding and fission yeasts, fungi synthesize their own iron siderophores (Haas, 2014). Coprogen B and ferrichrome were identified as two $A$. niger iron siderophores (Franken et al., 2014). However, oxalate and citrate both have inherent chelating properties (Dutton and Evans, 1996; Gadd, 1999), and citrate is an established iron siderophore in various different plant and prokaryotic systems (Cox et al., 1970; Frost and Rosenberg, 1973; Cox, 1980; Guerinot et al., 1990; Silva et al., 2009). Therefore, we hypothesize that, besides coprogen B and ferrichrome, citrate could serve as additional $A$. niger iron siderophore.

In this study, we aim to further elucidate the link between iron limitation and increased $A$. niger citrate secretion. To this end, we measured citrate per glucose production of $A$. niger grown with varying iron concentrations and nitrogen sources, and established a direct link between citrate secretion and iron availability. We investigated the effect of iron limitation on the A. niger transcriptome, and found changes associated to biomass, iron siderophore, and citrate and oxalate biosynthesis genes. Finally, we found that $A$. niger can utilize Fe(III) citrate as iron source. Our results support the hypothesis that citrate acts as $A$. niger iron siderophore, and provide insights on why $A$. niger organic acid production is a $\mathrm{pH}$-dependent process.

\section{MATERIALS AND METHODS}

\section{Strains, Media, and Culture Conditions}

The A. niger strains N402 (cspA1), NW305 (cspA, goxC17, $\triangle \operatorname{argB})$ (Ruijter et al., 2003), and NW186 (cspA1, goxC17, prtF28, $\triangle \arg B, p y r A 6$ ), a $\triangle \arg B$ and $p y r A 6$ derivative of NW185 (Ruijter et al., 1999), were used for this study. For the growth experiments, A. niger NW186 was transformed as described (Kusters-van Someren et al., 1991) with the plasmid pGW635 (Goosen et al., 1989), carrying the pyrA gene of $A$. niger. This complements the pyrA6 transformation marker and restores the uridine prototrophy. In addition, we measured citrate production under low iron stress (no iron added to the medium, see Supplementary File 1) in A. niger NW129 (cspA1, goxC17, pyrA1) (Ruijter et al., 1997).

To obtain spores, A. niger was grown (from glycerol stock), for 4 days, on complete medium (CM) agar plates, containing, per $1000 \mathrm{~mL}: 2 \mathrm{~g}$ meat peptone, $1 \mathrm{~g}$ yeast extract, $1 \mathrm{~g}$ casamino acids, $0.3 \mathrm{~g}$ yeast ribonucleic acids, $15 \mathrm{~g}$ agar and minimal medium (MM) salts (MM salts, per 1,000 mL: $6 \mathrm{~g} \mathrm{NaNO}, 1.5 \mathrm{~g} \mathrm{KH}_{2} \mathrm{PO}_{4}$, $0.5 \mathrm{~g} \mathrm{KCl}$, and $0.5 \mathrm{~g} \mathrm{MgSO}_{4} 7 \mathrm{H}_{2} \mathrm{O}$ ), added before sterilization, and $1 \mathrm{~mL}$ vitamin solution (composition of vitamin solution, per $100 \mathrm{~mL}: 0.01 \mathrm{~g}$ thiamine, $0.10 \mathrm{~g}$ riboflavin-5P, $0.01 \mathrm{~g} \mathrm{p}$ aminobenzoic acid, $0.10 \mathrm{~g}$ nicotinamide, $0.05 \mathrm{~g}$ pyridoxine- $\mathrm{HCl}$, $0.01 \mathrm{~g}$ pantothenic acid, $0.002 \mathrm{~g}$ biotin), $1 \mathrm{~mL}$ Vishniac (Vishniac and Santer, 1957) solution, $50 \mathrm{mM}(9 \mathrm{~g})$ glucose, and $0.02 \%$ arginine, added after sterilization. After 4 days of growth, spores were harvested with $12-13 \mathrm{~mL}$ of Saline-Tween solution.

A total of $10^{6}$ spores $/ \mathrm{mL}$ were inoculated in $1 \mathrm{~L}$ Erlenmeyer flasks containing $200 \mathrm{~mL}$ of $A$. niger production medium (PM, per 1,000 mL: $1.2 \mathrm{~g} \mathrm{NaNO}_{3}$ or $0.93 \mathrm{~g}\left(\mathrm{NH}_{4}\right)_{2} \mathrm{SO}_{4}, 0.5 \mathrm{~g} \mathrm{KH}_{2} \mathrm{PO}_{4}$, $\left.0.2 \mathrm{~g} \mathrm{MgSO}_{4} \cdot 7 \mathrm{H}_{2} \mathrm{O}\right), 100 \mathrm{mM}\left(\sim 20 \mathrm{~g} / \mathrm{L}^{-1}\right)$ glucose, $40 \mu \mathrm{L}$ adjusted Vishniac (Vishniac and Santer, 1957) solution (with, per $1000 \mathrm{~mL}$ : either $1.0 \mathrm{~g}(+)$ or $10 \mathrm{~g}(++) \mathrm{FeSO}_{4} \cdot 7 \mathrm{H}_{2} \mathrm{O}$, or $0.94 \mathrm{~g}$ (+) or $9.75 \mathrm{~g}(++) \mathrm{C}_{6} \mathrm{H}_{5} \mathrm{FeO}_{7} \cdot \mathrm{H}_{2} \mathrm{O}$ (Fe(III) citrate), or no Fe $(-)$ ), and $0.02 \%$ arginine (NW305, NW186) supplement. Note that, for a better understanding of the system, yeast extract was not used in any of the experiments. No measures were taken to keep the medium completely free from trace amounts of iron. The conditions referred to as -Fe describe a condition in which no iron was added to the medium, and shows the response of A. niger to low iron stress rather than the response of this fungus to complete absence of iron.

Time course experiments were performed in duplicates in a shake flask incubator at $30^{\circ} \mathrm{C}$ and $200 \mathrm{rpm}$. Supernatant samples were taken every $24 \mathrm{~h}$. Mycelial dry weight was measured after $96 \mathrm{~h}$.

The yeast strains Cyberlindnera jadinii DSM 2361, Cyberlindnera fabianii CBS 5640, Hanseniaspora uvarum CECT 11105, Kluyveromyces lactis CBS 739, Saccharomyces cerevisiae NCYC 2826, Wickerhamomyces anomalus DSM 6766, and Wickerhamomyces ciferii CBS 111 were grown (from glycerol stock) on yeast extract peptone dextrose plates (YPD, per 1,000 $\mathrm{mL}: 10 \mathrm{~g}$ yeast extract, $20 \mathrm{~g}$ peptone, $20 \mathrm{~g}$ glucose and $15 \mathrm{~g}$ agar) and, per 1,000 mL: $0.15 \mathrm{~g}$ uracil, $0.5 \mathrm{~g}$ leucine, $0.075 \mathrm{~g}$ tryptophan and $12.5 \mathrm{~g}$ histidine supplements. From these plates, overnight 
cultures were grown in $10 \mathrm{~mL}$ liquid YPD medium with the appropriate supplements (see below). The cultures were spun down, washed with sterile demi water, and resuspended in $10 \mathrm{~mL}$ demi water. $100 \mu \mathrm{L}$ of the resuspension was used to inoculate $100 \mathrm{~mL}$ Erlenmeyer flasks (in duplicate) containing $20 \mathrm{~mL}$ of medium (per 1,000 mL: $20 \mathrm{~g}$ glucose, $5 \mathrm{~g}\left(\mathrm{NH}_{4}\right)_{2} \mathrm{SO}_{4}$, $3 \mathrm{~g} \mathrm{KH}_{2} \mathrm{PO}_{4}$, and $0.5 \mathrm{~g} \mathrm{MgSO}_{4} \cdot 7 \mathrm{H}_{2} \mathrm{O}$, the same supplements mentioned before, and $40 \mu \mathrm{L}$ Verduyns (Verduyn et al., 1992) trace metal solution, either with or without $\mathrm{FeSO}_{4} \cdot 7 \mathrm{H}_{2} \mathrm{O}$, or 40 $\mu \mathrm{L}$ Verduyns (Verduyn et al., 1992) trace metal solution without $\mathrm{FeSO}_{4} \cdot 7 \mathrm{H}_{2} \mathrm{O}$, but $0.12 \mathrm{mg} / \mathrm{L} \mathrm{C}_{6} \mathrm{H}_{5} \mathrm{FeO}_{7} \cdot \mathrm{H}_{2} \mathrm{O}$ (Fe(III) citrate).

\section{Metabolite Analysis using HPLC}

Extracellular metabolite concentrations were determined by high-performance liquid chromatography (HPLC). An ICS5000 HPLC (Thermo Scientific), equipped with an Aminex HPX-87H column (BioRad) at $60^{\circ} \mathrm{C}$, and coupled to a refractive index detector (Shodex RI-101, sample frequency $5 \mathrm{~Hz}$ ) and a Thermo UV/VIS detector $(\lambda=210 \mathrm{~nm})$, was used. Separations were performed by elution with $0.016 \mathrm{~N} \mathrm{H}_{2} \mathrm{SO}_{4}$ at a flow rate of $0.6 \mathrm{~mL} / \mathrm{min}$. An organic acid standard, containing oxalic acid, citric acid, malic acid, succinic acid and itaconic acid, and a separate glucose standard, with 2, 5, 10, and $20 \mathrm{mM}$ (both organic acid standard and glucose standard), 100 and $200 \mathrm{mM}$ (only glucose standard) were used to calculate calibration curves for quantification of the extracellular metabolite concentrations. Measurement of known concentrations of a $\mathrm{Fe}(\mathrm{III})$ citrate standard matched the areas under the peak for the normal citrate standard. Propionic acid $(6 \mathrm{mM})$ was used as an internal standard.

\section{Siderophore Detection}

Total siderophore concentration in the A. niger culture medium was quantified using the SideroTec Assay ${ }^{\mathrm{TM}}$ (Emergen Bio, Maynooth University, Kildare, Ireland), following the protocol provided. The samples were adjusted to the proper $\mathrm{pH}$ range for the assay ( $\mathrm{pH} \mathrm{6-8)} \mathrm{by} \mathrm{diluting} \mathrm{all} \mathrm{samples} \mathrm{and} \mathrm{standards}$ 40:60 with $1 \mathrm{M}$ Tris- $\mathrm{HCl}, \mathrm{pH} 7.0(40 \mu \mathrm{L}$ Tris- $\mathrm{HCl}+60 \mu \mathrm{L}$ sample/standard). Samples and standards were measured on a microplate reader (Elx808) at OD650.

\section{RNA Isolation and Quality Control}

RNA extraction was performed using the Maxwell ${ }^{\circledR} 16 \mathrm{LEV}$ simplyRNA Tissue kit (Promega). Frozen mycelium $(\approx 100 \mathrm{mg})$ of the sample was submerged in $400 \mu \mathrm{L}$ Homogenizing buffer supplemented with $8 \mu \mathrm{L}$ 1-thioglycerol in a $2 \mathrm{~mL}$ Lysing matrix $\mathrm{C}$ tube (MP), prefilled with a mix of glass beads. Mycelium samples were disrupted using a FastPrep-24 instrument (MP). After disruption all liquid was transferred to a LEV RNA Cartridge. $200 \mu \mathrm{L}$ lysis buffer was added and the rest of the extraction was performed by a Maxwell MDx AS3000 machine (Promega) following the protocol. RNA integrity and quantity were assessed with an Experion system (Bio-Rad), and only high quality samples (RIN value $\geq 7$ ) were selected. Total RNA was sent directly to BaseClear (Leiden, The Netherlands) for whole transcriptome shotgun sequencing.

\section{RNA Sequencing and Quality Check}

RNA sequencing (RNA seq) and initial quality check was performed by BaseClear, and was reported as follows: "Singleend sequence reads were generated using the Illumina HiSeq2500 system. FASTQ sequence files were generated using the Illumina Casava pipeline version 1.8.3. Initial quality assessment was based on data passing the Illumina Chastity filtering. Subsequently, reads containing adapters and/or PhiX control signal were removed using an in-house filtering protocol. The second quality assessment was based on the remaining reads using the FASTQC quality control tool version 0.10.0."

\section{RNA seq Data Processing}

The RNA seq reads were filtered using SortMeRNA v1.9 (Kopylova et al., 2012) and Trimmomatic v0.32 (Bolger et al., 2014). Read mapping against A. niger ATCC 1015 (Andersen et al., 2011; Nordberg et al., 2014), was performed using STAR v2.5.0c (Dobin et al., 2013). Gene coverage calculations were performed using BEDTools v2.17.0 (Quinlan and Hall, 2010), and subsequently normalized for the respective library sizes. Differential expression analysis was performed using the $\mathrm{R}$ package edgeR (Robinson et al., 2009). RNA seq normalization and differential expression was performed simultaneously for each comparison. Genes with a count per million $(\mathrm{CPM}) \geq 1$ in at least two samples were considered to be expressed and kept for further analysis. Trimmed mean of M-values normalization was performed as implemented in the $\mathrm{R}$ package edgeR. $P$ values were corrected for multiple testing using the BenjaminiHochberg procedure. The terms "differentially expressed" and "overexpressed" refer to differences in read counts per CDS, and denote a fold-change $\geq 1.5$ (FDR $\leq 0.05)$. A detailed pipeline of the RNA seq data processing can be found in Supplementary File 2. The aligned.bam files have been submitted to the European Nucleotide Archive (ENA), and can be found under the accession number PRJEB20746.

\section{Enrichment Analyses}

The protein products of the expressed genes were annotated using PRIAM (Claudel-Renard et al., 2003), and subsequently assigned to KEGG pathway maps (Kanehisa and Goto, 2000; Kanehisa et al., 2015). Metabolic pathway enrichment analysis was performed using the hypergeometric test implementation ("phyper") of the R software environment (R Core, 2014).

Protein localization prediction was performed with the Softberry protComp tool (www.softberry.com). Enrichment analysis was performed on differentially expressed genes per organelle as described above.

\section{RESULTS}

\section{A. niger Iron-Dependent Biomass and Citrate Production}

When grown in a culture medium with glucose as sole carbon source, wild type $A$. niger strains secrete multiple organic acids (Figure 1). Under moderate acidic conditions ( $\mathrm{pH}$ 5), mainly oxalic acid is secreted. Additionally, glucose is converted extracellularly to gluconate by a secreted glucose oxidase. Upon 


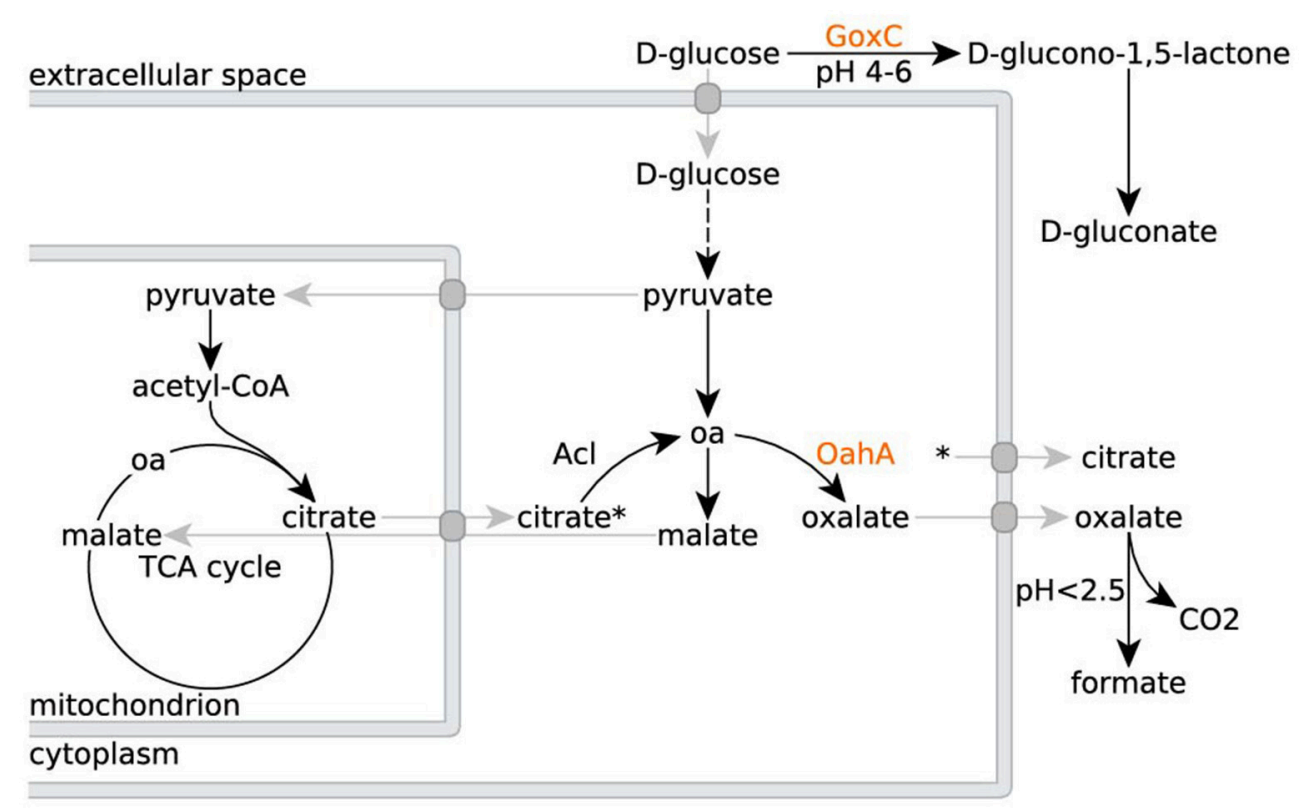

FIGURE 1 | Organic acid production in A. niger N402 and its derivatives. Metabolic routes for citrate, oxalate and gluconate production in A. niger N402 and its derivatives (oa = oxaloacetate). Mutants defective in GoxC can no longer produce gluconate, whereas mutants defective in OahA can no longer produce oxalate. A hypothetical malate/citrate antiport (Karaffa and Kubicek, 2003), and other transport processes, are depicted in gray. Citrate export is indicated by the asterisk.

further acidification of the medium to a $\mathrm{pH}$ below 2.5 , citrate becomes the predominantly secreted organic acid (Ruijter et al., 1999). To remove gluconate and oxalate as confounding factors, but without having to exert control over the external $\mathrm{pH}$ and thereby influencing iron availability, we worked with $A$. niger strain NW186. This strain bears two mutations, one leading to a frameshift in the gene encoding glucose oxidase (goxC17), and a nonsense mutation in the gene encoding oxaloacetate hydrolase $(o a h A)$, making this strain a gluconate and oxalate non-producer (Ruijter et al., 1999; Han et al., 2007).

Another confounding factor is that iron, zinc, copper, manganese, phosphorus, magnesium, potassium, and nitrogen limitation reportedly all have a stimulating effect on $A$. niger organic acid production (Chesters and Rolinson, 1951; Kubicek and Röhr, 1977). Thus, we grew NW186 with different nitrogen sources, and varying amounts of iron sulfate $\left(\mathrm{Fe}(\mathrm{II}) \mathrm{SO}_{4}\right)$ added to the medium, but otherwise identical growth conditions (see Materials and Methods). A. niger biomass production increases with the amount of iron added to the medium (Table 1) and, in contrast to previous findings (Currie, 1917), this happens irrespective of whether nitrogen is supplied as nitrate $\left(\mathrm{NaNO}_{3}\right)$ or ammonium $\left(\left(\mathrm{NH}_{4}\right)_{2} \mathrm{SO}_{4}\right)$. Note that no special measures were taken to keep the cultures completely free from any traces of iron, which will most likely be present. However, the increasing biomass upon addition of more iron to the medium (Table 1) shows that, in our experimental setup, iron is the growth-limiting factor; the observations described are thus a direct effect of the amount of $\mathrm{Fe}(\mathrm{II}) \mathrm{SO}_{4}$ added to the medium.

In contrast to the increase in $A$. niger biomass production (Table 1), and again irrespective of whether nitrogen is supplied as $\mathrm{NaNO}_{3}$ or $\left(\mathrm{NH}_{4}\right)_{2} \mathrm{SO}_{4}$, increasing the amount of $\mathrm{Fe}(\mathrm{II}) \mathrm{SO}_{4}$ decreases citrate per glucose production in NW186 (Figure 2A). In addition, we found that NW186 pre-grown without iron stopped secreting citrate after $\mathrm{Fe}(\mathrm{II}) \mathrm{SO}_{4}$ was added to the culture medium (Figure 2B). Final biomass reached $0.93 \pm 0.02 \mathrm{~g} / \mathrm{L}$ and $0.71 \pm 1 \mathrm{e}-3 \mathrm{~g} / \mathrm{L}$ in the cultures grown with and without $\mathrm{Fe}(\mathrm{II}) \mathrm{SO}_{4}$ added to the medium, respectively.

Compared to NW186, decreasing the amount of iron added to the medium did not have an as equally pronounced effect on total citrate per glucose production in the two control strains N402 and NW305 (Figure 3). The direct relationship between iron limitation and citrate secretion is expected to be less straightforward in $A$. niger strains that are able to produce multiple organic acids in major quantities, and the shared relationship of iron on organic acid production is suggested by the secretion pattern of oxalate in NW305, where decreasing iron availability increases both oxalate and citrate per glucose production (Figure 3B).

\section{A. niger Iron-Dependent Gene Expression of Biomass, Iron Siderophore, and Citrate Biosynthesis Genes}

The shared relationship of iron on both citrate and oxalate secretion in NW305 (Figure 3B), especially in comparison to the direct relationship of iron on citrate secretion in NW186 (Figure 2A) suggests that increased citrate secretion in NW186 is a result of impaired oxalate secretion due to the OahA mutation. This suggests a lesser role of citrate in wild-type strains of $A$. niger, especially before medium acidification to $\mathrm{pH} \leq 2.5$, where 
TABLE 1 | Final biomass [g/L] of A. niger NW186 and the two control strains N402 and NW305 grown with different nitrogen sources and varying iron concentrations in the medium (Fe source: $\mathrm{Fe}(\mathrm{II}) \mathrm{SO}_{4}$ ).

\begin{tabular}{|c|c|c|c|c|c|c|}
\hline \multirow[t]{2}{*}{ Strain (major organic acid(s) produced) } & \multicolumn{3}{|c|}{$\mathrm{N}$ source: $\mathrm{NaNO}_{3}$} & \multicolumn{3}{|c|}{$\mathrm{N}$ source: $\left(\mathrm{NH}_{4}\right)_{2} \mathrm{SO}_{4}$} \\
\hline & $-\mathrm{Fe}$ & $+\mathrm{Fe}$ & $++F e$ & $-\mathrm{Fe}$ & $+\mathrm{Fe}$ & $++\mathrm{Fe}$ \\
\hline N402 (gluconate, oxalate, citrate) & $0.39 \pm 0.01$ & $0.66 \pm 1 e-3$ & $1.52 \pm 3 e-3$ & $0.51 \pm 1 e-3$ & $1.48 \pm 3 e-3$ & $2.34 \pm 0.01$ \\
\hline NW305 (oxalate, citrate) & $0.97 \pm 0.02$ & $1.08 \pm 0.04$ & $1.73 \pm 0.02$ & $0.91 \pm 0.01$ & $1.97 \pm 0.02$ & $3.45 \pm 1 e-3$ \\
\hline NW186 (citrate) & $1.09 \pm 1 e-3$ & $1.58 \pm 0.01$ & $1.84 \pm 1 e-3$ & $0.89 \pm 0.01$ & $2.17 \pm 0.03$ & $3.39 \pm 0.08$ \\
\hline
\end{tabular}
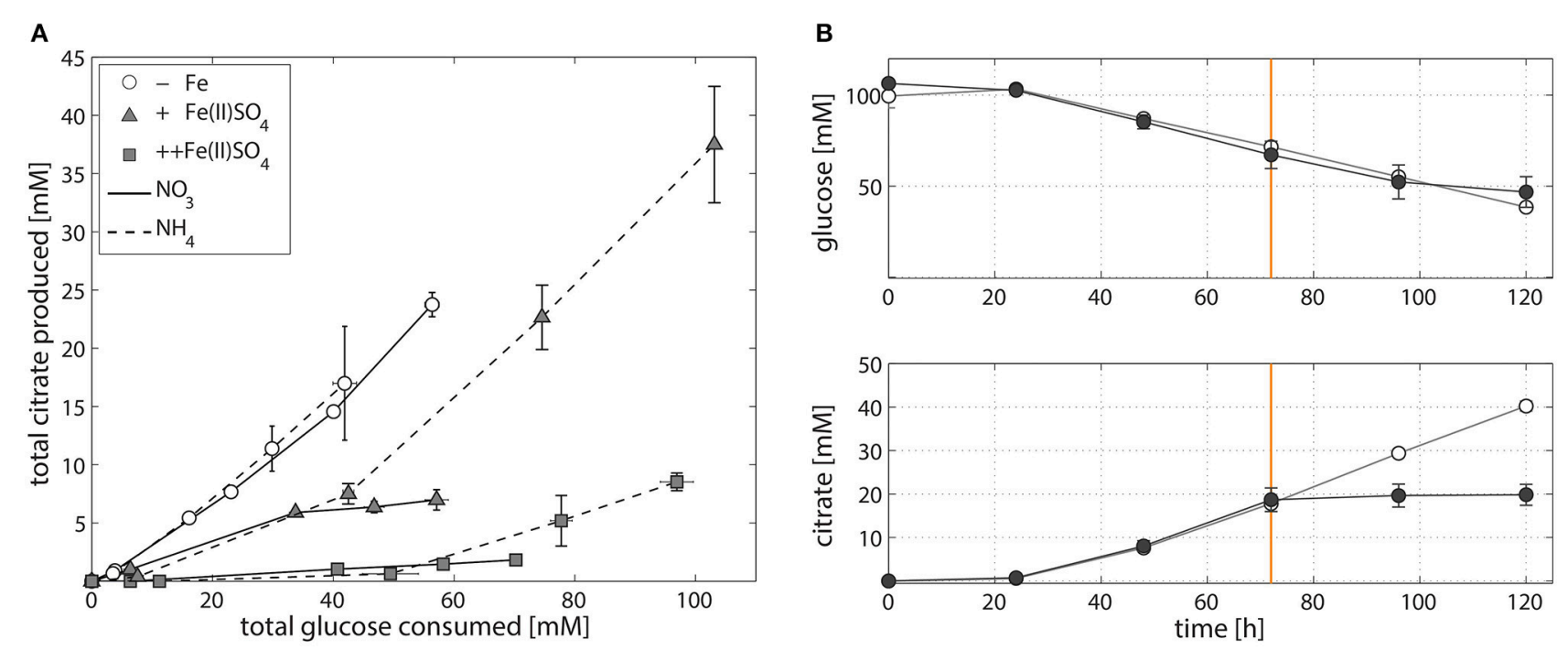

FIGURE 2 | Iron-dependent citrate production of $A$. niger NW186. (A) Total citrate production per glucose consumption of $A$. niger NW186, grown without addition of iron (empty circles), or varying amounts of $\mathrm{Fe}(\mathrm{II}) \mathrm{SO}_{4}$ (triangles = iron limited, squares = iron excess), and either $\mathrm{NaNO}_{3}\left(\mathrm{solid}\right.$ line) or $\left(\mathrm{NH}_{4}\right)_{2} \mathrm{SO}_{4}($ dashed line) as nitrogen source. (B) Total glucose and citrate concentration of $A$. niger NW186 grown with (filled symbols) or without (empty symbols) Fe(II)SO $\mathrm{S}_{4}$ added to the medium at $t=72 \mathrm{~h}$ (orange line), and $\mathrm{NaNO}_{3}$ as nitrogen source. Measurement points were taken once every $24 \mathrm{~h}$ and show the average of two biological replicates. The error bars indicate the estimation of standard deviation divided by the number of replicates ( $\mathrm{N}$ ) rather than $\mathrm{N}-1$.

citrate starts to take over as primary organic acid secreted even in wild type strains (Currie, 1917). To gain further insights into the adaptations to iron limitation, especially with regard to the organic acid secreted, of the oxalate-impaired (hence citrate producing) NW186 mutant, we compared the transcriptional response of NW186 grown without iron added to the medium (NW186 - Fe) to the control strain NW305 grown without iron $(\mathrm{NW} 305-\mathrm{Fe})$ or excess iron $(\mathrm{NW} 305++\mathrm{Fe})$ added to the medium (Figure 4).

The RNA seq reads obtained from the different conditions were mapped against the annotated A. niger ATCC 1015 genome (Andersen et al., 2011). Of the 11910 ATCC 1015 reference genes, reads were mapped (with a count per million $(\mathrm{CPM}) \geq 1$ ) to 9239, 8687 and 8815 genes in NW305 ++Fe, NW305 -Fe and NW186 - Fe, respectively (Table 2). Of the genes expressed, 3332 were differentially expressed (FDR $\leq 0.05$ ) between the control NW305 ++Fe vs. NW305 - Fe, and 1252 were differentially expressed $(\mathrm{FDR} \leq 0.05)$ between NW186 $-\mathrm{Fe}$ vs. NW305 $-\mathrm{Fe}$ (Table 2, Supplementary File 3).

Conforming the results presented in Table 1, metabolic pathway enrichment analysis (Supplementary File 4) showed that addition of iron to the $A$. niger culture medium has the strongest effect on biosynthesis pathways leading to biomass formation, i.e., starch and sucrose metabolism, and biosynthesis of various amino acids is up-regulated in iron replete vs. iron deplete conditions (i.e., in NW305 ++Fe compared to NW305 $-\mathrm{Fe}$ ). In addition, fatty acid biosynthesis showed enrichment of differentially expressed genes between NW305 ++Fe and NW305 - Fe. In comparison, the biggest difference between NW186 - Fe and NW305 - Fe was related to lipoic and steroid biosynthesis, and drug and xenobiotics metabolism pathways.

We analyzed expression levels of $A$. niger genes reported to be involved in iron homeostasis and siderophore biosynthesis (Haas, 2012; Franken et al., 2014). In agreement with (Haas, 2003; Franken et al., 2014), A. niger iron siderophore biosynthesis shows a clear response to iron limitation at transcriptional level (Figure 5, Supplementary File 5). The difference in iron siderophore biosynthesis is also reflected in the total amount of iron chelating compounds in the A. niger supernatant (Table S1 in Supplementary file 6). As can be seen in Table S1, A. niger secretes more iron chelating compounds under iron limited conditions, and the concentration of these compounds increases over time. 

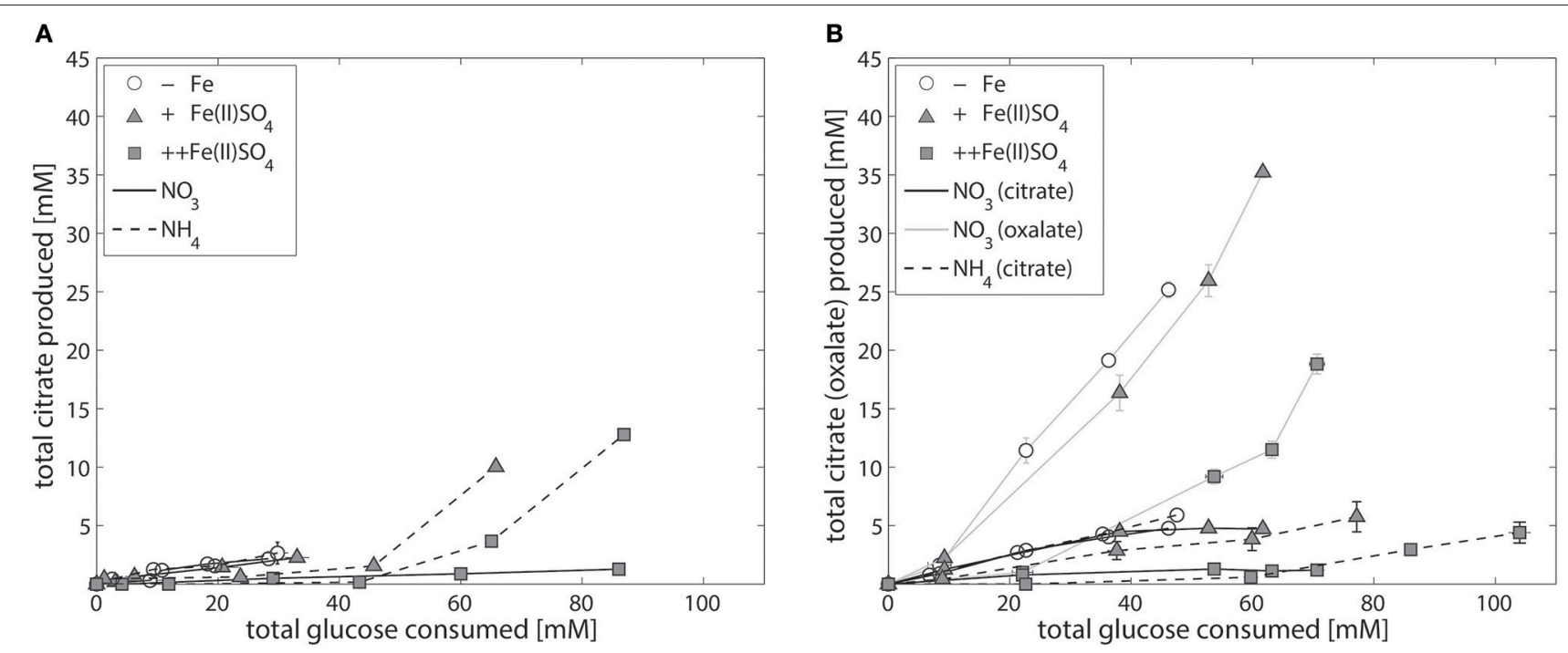

FIGURE 3 | Iron-dependent citrate production of the control strains A. niger N402 and NW305. Total citrate production per glucose consumption of the control strains

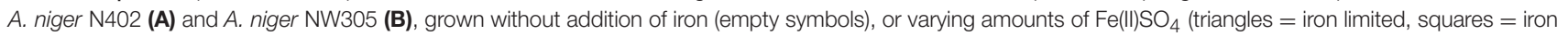
excess), and either $\mathrm{NaNO}_{3}$ (solid line) or $\left(\mathrm{NH}_{4}\right)_{2} \mathrm{SO}_{4}$ (dashed line) as nitrogen source. Note that iron-dependent total oxalate per glucose production (gray, solid line) was plotted as example for one experiment (NW305, $\mathrm{N}$ source $=\mathrm{NaNO}_{3}$ ). Measurement points were taken once every $24 \mathrm{~h}$ and show the average of two biological replicates. The error bars indicate the estimation of standard deviation divided by the number of replicates $(\mathrm{N})$ rather than $\mathrm{N}-1$.

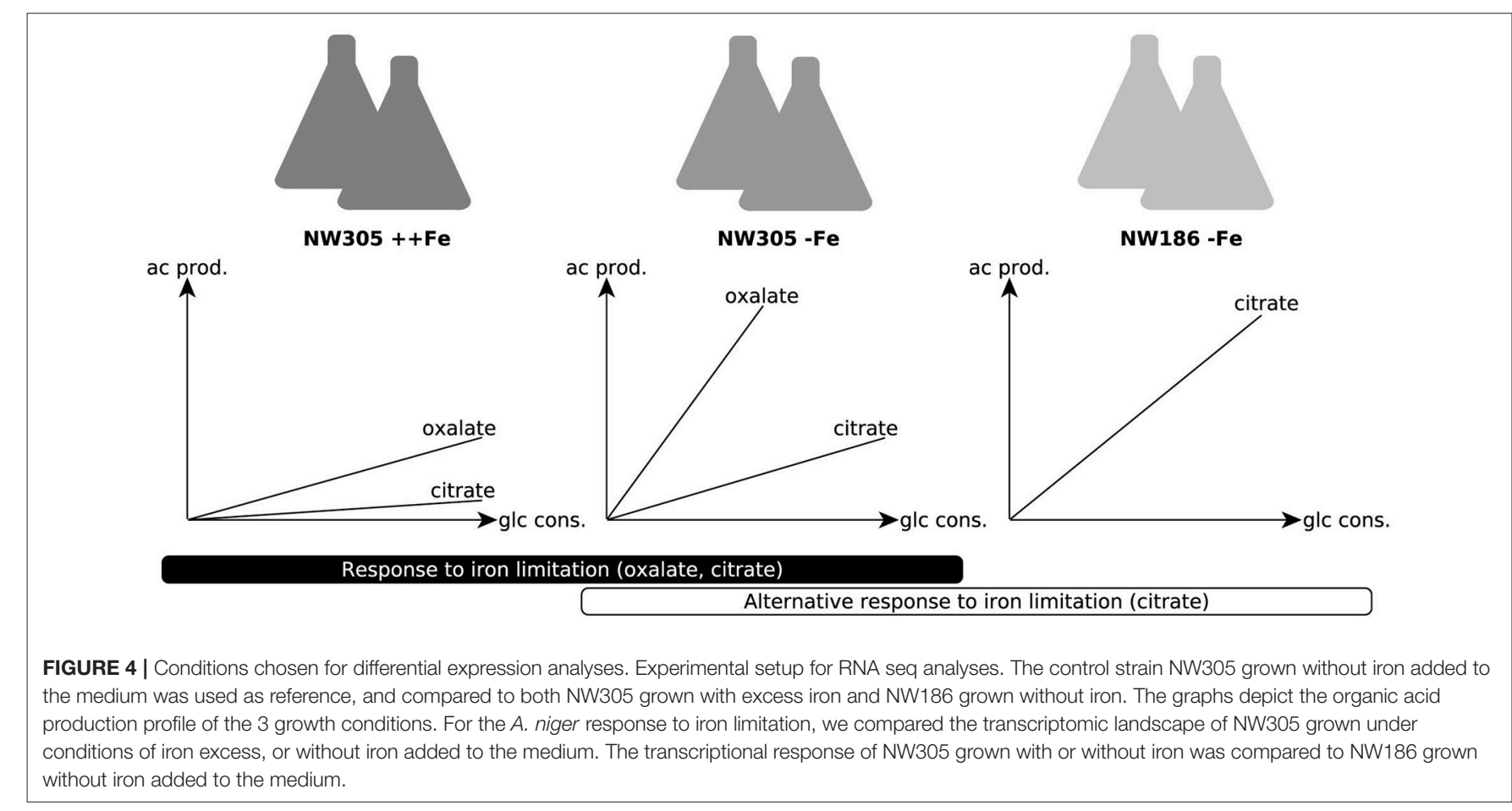

Note that most of the proteins listed in Supplementary File 5 are based on best bi-directional Blast hits with the A. niger CBS 513.88 proteins identified by Franken et al. (2014). We included 1181156 (ATCC 1015 transId 1181432) in the list as possible transcriptional factor related to iron homeostasis and/or organic acid production due to its high expression level and pattern of transcription. 1181156 has a similar basic helix-loop-helix structure as the known A. fumigatus transcription factor SrbA, which was found to be essential for adaptation of this fungus to low iron stress (Blatzer et al., 2011). In addition, we included all ATCC 1015 proteins with putative metalloreductase/ferric (chelate) reductase activity in the list (Supplementary File 5), and indicated which enzymes use iron as a co-factor (Supplementary File 3). In the ATCC 1015 in silico proteome, there are 163 
TABLE 2 | RNA seq mapping and differential expression analyses.

\begin{tabular}{|c|c|c|c|}
\hline Strain and culture condition & NW305 ++Fe & NW305 -Fe & $\mathrm{NW} 186-\mathrm{Fe}$ \\
\hline \multirow{2}{*}{$\begin{array}{l}\text { \# Reads after QC filtering (see } \\
\text { Supplementary File 2) }\end{array}$} & $51,965,960(1)$ & $45,240,789(1)$ & $43,227,405(1)$ \\
\hline & $29,101,217$ (2) & $52,325,240(2)$ & $57,754,970(2)$ \\
\hline \multirow{2}{*}{$\begin{array}{l}\text { Uniquely mapped reads (against } \\
\text { ATCC1015 CDS) }\end{array}$} & $57.96 \%(1)$ & $71.49 \%(1)$ & $68.82 \%(1)$ \\
\hline & $61.22 \%(2)$ & $73.13 \%(2)$ & $72.70 \%(2)$ \\
\hline \# Genes expressed (CPM $\geq 1)$ & 9239 & 8687 & 8815 \\
\hline $\begin{array}{l}\text { \# Genes differentially expressed, } \\
\log _{2} F C \text { threshold } \geq 0.58 \\
(F D R \leq 0.05)\end{array}$ & 333 & \multicolumn{2}{|c|}{1252} \\
\hline
\end{tabular}

\section{\# EC covered (mapped to KEGG}

pathways)

465

\# EC differentially expressed,

$\log _{2} \mathrm{FC}$ threshold $\geq 0.58$

$(\mathrm{FDR} \leq 0.05)$

83

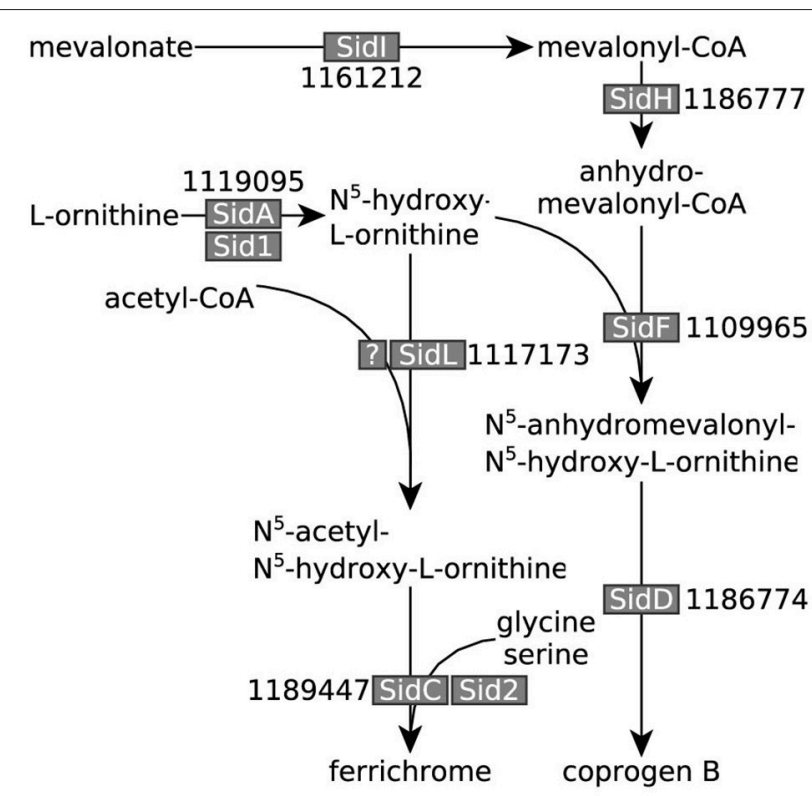

FIGURE 5 | A. niger iron siderophore biosynthesis pathway. Iron siderophore biosynthesis genes identified in A. niger (adapted from Haas, 2012 and Franken et al., 2014). A. niger ATCC 1015 transcript identifiers are denoted next to the names of the enzymes given in other fungi. All genes, except the gene encoding the elusive $A$. niger SidL homolog, were overexpressed under iron limited conditions.

enzymes that interact with iron as ligand according to the BRENDA database (Schomburg et al., 2004) of which 58 were differentially expressed (FDR $\leq 0.05)$ between NW305 $++\mathrm{Fe}$ vs. NW305 $-\mathrm{Fe}$, although there was no clear pattern of up- or down-regulation in response to the amount of iron added to the medium (i.e., 23 enzymes were up-regulated in NW305 ++Fe, and 32 were down-regulated; see Supplementary File 3).

Similar as for iron siderophore biosynthesis genes (Figure 5, Supplementary File 5), we found that both citrate synthase (citA, EC 2.3.3.1) and oahA (EC 3.7.1.1) were transcriptionally up-regulated in response to low iron stress (Table 3). In addition, ATP-citrate lyase (EC 2.3.3.8) and, to a lesser extent, $\left(\mathrm{NAD}^{+}\right)$isocitrate dehydrogenase were transcriptionally upregulated in response to low iron stress (Table 3 ). In contrast, expression of citrate metabolizing enzymes aconitase (EC 4.2.1.3) and $\left(\mathrm{NADP}^{+}\right)$isocitrate dehydrogenase (NADP-IDH, EC 1.1.1.42) did not show exclusively iron-dependent transcriptional regulation; most expressed isozymes were up-regulated in the reference NW305 - Fe compared to both NW305 ++Fe and NW186 -Fe (Table 3).

Organelle specific differential expression enrichment analysis revealed the biggest difference between the 3 conditions was found in the plasma membrane (Table 4). Additionally, we observed enrichment of differentially expressed peroxisomal proteins in response to iron availability in the medium, i.e., in NW305 ++Fe vs. NW305 $-\mathrm{Fe}$, but not in NW186 $-\mathrm{Fe}$ vs. NW305 -Fe (Table 4). These differences could be attributed to the finding that many enzymes that participate in fungal iron siderophore biosynthesis are located in peroxisomes (Gründlinger et al., 2013). In addition, peroxisomes participate in metabolism of oxygen metabolites (Schrader and Fahimi, 2006). Under iron excess, low affinity ferrous iron uptake might lead to an excess of $\mathrm{Fe}$ (II) in the cell, which can catalyze the Fenton reaction: $\mathrm{Fe}(\mathrm{II})+\mathrm{H}_{2} \mathrm{O}_{2} \rightarrow \mathrm{Fe}(\mathrm{III})+\mathrm{OH}^{-}+{ }^{\cdot} \mathrm{OH}$. The resulting oxygen radical $\mathrm{OH}$ can have cell-damaging effects (Schrader and Fahimi, 2006). However, if $\mathrm{H}_{2} \mathrm{O}_{2}$ can be decomposed to $\mathrm{O}_{2}$ and $\mathrm{H}_{2} \mathrm{O}$ by gluthatione-peroxidase (EC 1.11.1.9) or catalase (EC 1.11.1.6), the formation of $\mathrm{OH}$ can be prevented (Schrader and Fahimi, 2006). Although we could not identify an ATCC 1015 glutathione-peroxidase, there are 9 predicted catalases in the $A$. niger ATCC 1015 reference proteome (Supplementary File 3), of which 4 are predicted to be located in the peroxisome (1201726, not differentially expressed; 1116766, overexpressed in $++\mathrm{Fe}$ vs. $-\mathrm{Fe} ; 1119521$, overexpressed in $++\mathrm{Fe}$ vs. $-\mathrm{Fe} ; 1158108$, not differentially expressed), 3 are predicted to be cytosolic (1155727, not differentially expressed; 1137750, underexpressed in $++\mathrm{Fe}$ vs. $-\mathrm{Fe} ; 1228383$, not differentially expressed) and one each mitochondrial (1181451, overexpressed in $++\mathrm{Fe}$ vs. $-\mathrm{Fe}$ ) or secreted (1204436, overexpressed in $++\mathrm{Fe}$ vs. $-\mathrm{Fe}$ ). Another peroxisomal enzyme that had an interesting expression pattern was pyruvate oxidoreductase (EC 1.2.7.1, transcriptId: 1162221, proteinId: 1161945), which was overexpressed in both NW186 - Fe and NW305 ++Fe compared to NW305 $-\mathrm{Fe}$ (Supplementary file 3).

\section{$\mathrm{Fe}(\mathrm{III})$ Citrate as Iron Source for A. niger and Yeast-Type Fungi}

Finally, we investigated whether $A$. niger has the means to deal with citrate bound iron as iron source, and found that addition of $\mathrm{Fe}$ (III) citrate to the medium alleviates iron limitation and restores the growth phenotype (Table 5). In addition, the amount 
TABLE 3 | Differentially expressed enzymes involved in citrate and oxalate metabolism.

\begin{tabular}{|c|c|c|c|c|}
\hline $\begin{array}{l}\text { ATCC } 1015 \text { transcriptld, } \\
\text { proteinld }\end{array}$ & $\begin{array}{l}\text { Predicted } \\
\text { EC number }\end{array}$ & Enzyme name & $\begin{array}{c}\log _{2} \mathrm{FC} \text { NW305 ++Fe vs. } \\
\text { NW305 -Fe (FDR) }\end{array}$ & $\begin{array}{c}\log _{2} \mathrm{FC} \text { NW186 -Fe vs. } \\
\text { NW305 -Fe (FDR) }\end{array}$ \\
\hline 1141647,1141371 & 2.3.3.1 & Citrate synthase & $-1.222(0.002)$ & $-0.167(0.949)$ \\
\hline $\begin{array}{l}\text { 1218960, 1218684; } \\
\text { 1148603, 1148327; } \\
\text { 1181034, } 1180758\end{array}$ & 4.2.1.3 & Aconitase & $\begin{array}{c}0.237(0.770) ; \\
-0.763(0.114) ; \\
0.398(0.556)\end{array}$ & $\begin{array}{l}-0.984(0.124) \\
-0.984 \text { (0.055); } \\
-0.841(0.079)\end{array}$ \\
\hline 1175666,1175390 & 1.1.1.42 & $\left(\mathrm{NADP}^{+}\right)$isocitrate dehydrogenase & $-2.033(0.000)$ & $-1.135(0.022)$ \\
\hline $\begin{array}{l}\text { 1111634, 1111358; } \\
\text { 1147138, } 1146862\end{array}$ & 2.3.3.8 & ATP-citrate lyase & $\begin{array}{l}-1.381(0.000) \\
-1.178(0.005)\end{array}$ & $\begin{array}{l}-0.026(0.994) \\
0.193(0.934)\end{array}$ \\
\hline
\end{tabular}

TABLE 4 | Organelle specific differential expression enrichment analysis.

\begin{tabular}{|c|c|c|c|}
\hline Organelle & $\begin{array}{l}\text { \# Genes } \\
\text { expressed } \\
(\mathrm{CPM} \geq 1)\end{array}$ & $\begin{array}{c}\text { \# Genes differentially } \\
\text { expressed, } \log _{2} F C \text { threshold } \\
\geq 0.58(F D R \leq 0.05)\end{array}$ & $p$-value \\
\hline \multicolumn{4}{|c|}{ NW305 ++Fe vs. NW305 $-\mathrm{Fe}(\mathrm{N}=5658, k=2231)$} \\
\hline Cytoplasm & 1988 & 788 & 0.42 \\
\hline Endoplasmic reticulum & 363 & 123 & 0.99 \\
\hline Golgi & 227 & 78 & 0.95 \\
\hline Mitochondrion & 1794 & 684 & 0.92 \\
\hline Peroxisome & 146 & 68 & 0.05 \\
\hline Plasma membrane & 1140 & 490 & $3 e-3$ \\
\hline \multicolumn{4}{|c|}{ NW186 $-\mathrm{Fe}$ vs. NW305 $-\mathrm{Fe}(\mathrm{N}=5641, k=852)$} \\
\hline Cytoplasm & 1993 & 279 & 0.96 \\
\hline Endoplasmic reticulum & 362 & 46 & 0.92 \\
\hline Golgi & 224 & 35 & 0.44 \\
\hline Mitochondrion & 1790 & 246 & 0.98 \\
\hline Peroxisome & 145 & 26 & 0.20 \\
\hline Plasma membrane & 1127 & 220 & $4 e-6$ \\
\hline
\end{tabular}

TABLE 5 | Final biomass [g/L] of A. niger NW305 and NW186 grown with Fe(III) citrate as iron source $\left(\mathrm{N}\right.$ source $\left.=\left(\mathrm{NH}_{4}\right)_{2} \mathrm{SO}_{4}\right)$.

\begin{tabular}{lccc}
\hline $\begin{array}{l}\text { Strain (major organic acid(s) } \\
\text { produced) }\end{array}$ & $-\mathbf{F e}$ & $+\mathbf{F e}$ & $++\mathbf{F e}$ \\
\hline NW305 (oxalate, citrate) & $0.78 \pm 4 \mathrm{e}-3$ & $1.86 \pm 0.01$ & $3.28 \pm 0.01$ \\
NW186 (citrate) & $0.84 \pm 3 e-3$ & $1.91 \pm 0.03$ & $3.09 \pm 0.01$ \\
\hline
\end{tabular}

of iron added as $\mathrm{Fe}(\mathrm{III})$ citrate has the same effect on citrate production per glucose consumed as observed with $\mathrm{Fe}(\mathrm{II}) \mathrm{SO}_{4}$ (Figure 6).

Most budding and fission yeasts, which do not produce own siderophores, are able to utilize iron complexed to xenosiderophores (Haas, 2014). To verify that Fe(III) citrate is a viable iron source for different yeast type fungi, we also tested the ability of Cyberlindnera jadinii, Cyberlindnera fabianii, Hanseniaspora uvarum, Kluyveromyces lactis, Saccharomyces cerevisiae, Wickerhamomyces anomalus, and Wickerhamomyces ciferii to grow on $\mathrm{Fe}(\mathrm{III})$ citrate as iron source. With the exception of $C$. jadinii, which could not grow when $\mathrm{Fe}(\mathrm{III})$ citrate was added to the medium, all the strains were able to grow in all the conditions tested (either $\mathrm{Fe}(\mathrm{II}) \mathrm{SO}_{4}, \mathrm{Fe}(\mathrm{III})$ citrate or no iron added to the medium).

\section{DISCUSSION}

\section{Citrate as Overflow Metabolite vs. Citrate as Biological Asset}

There are two possible interpretations for the results presented in Figure 2: (i) A. niger citrate production is a result of metabolic overflow triggered by carbon excess relative to low iron availability, or (ii) A. niger citrate production is a strategy to increase bioavailability of iron. The effect is essentially the same, only in hypothesis (i), citrate is regarded as a "waste product" for the fungus, whereas in hypothesis (ii), citrate is regarded as a biological asset enabling $A$. niger to cope with low iron stress.

To test which of these two hypotheses is more likely, we compared the responses of NW186 and NW305 to varying iron concentrations in the medium. Both of these strains are gluconate non-producers, and NW186 differs from its oxalate producing equivalent NW305 only by dysfunctional OahA (Ruijter et al., 1999; Han et al., 2007). This mutation deprives NW186 of the possibility to produce oxalate via the cytosolic route in which oxaloacetate is hydrolysed to oxalate and acetate (Figure 1); the established route of oxalate biosynthesis on glucose as carbon source (Kubicek et al., 1988). As a result, NW186 produces only citrate in major quantities, and decreasing the amount of iron added to the medium is directly reflected in increased citrate per glucose production in this mutant (Figure 2). In NW305, decreasing the amount of iron added to the medium increases both oxalate and citrate per glucose production (Figure 3).

According to hypothesis (i), citrate would thus be regarded as an overflow metabolite alternative to oxalate, implying that carbon flow directed toward oxalate in NW305 stops short at citrate in NW186, and that increased extracellular oxalate 

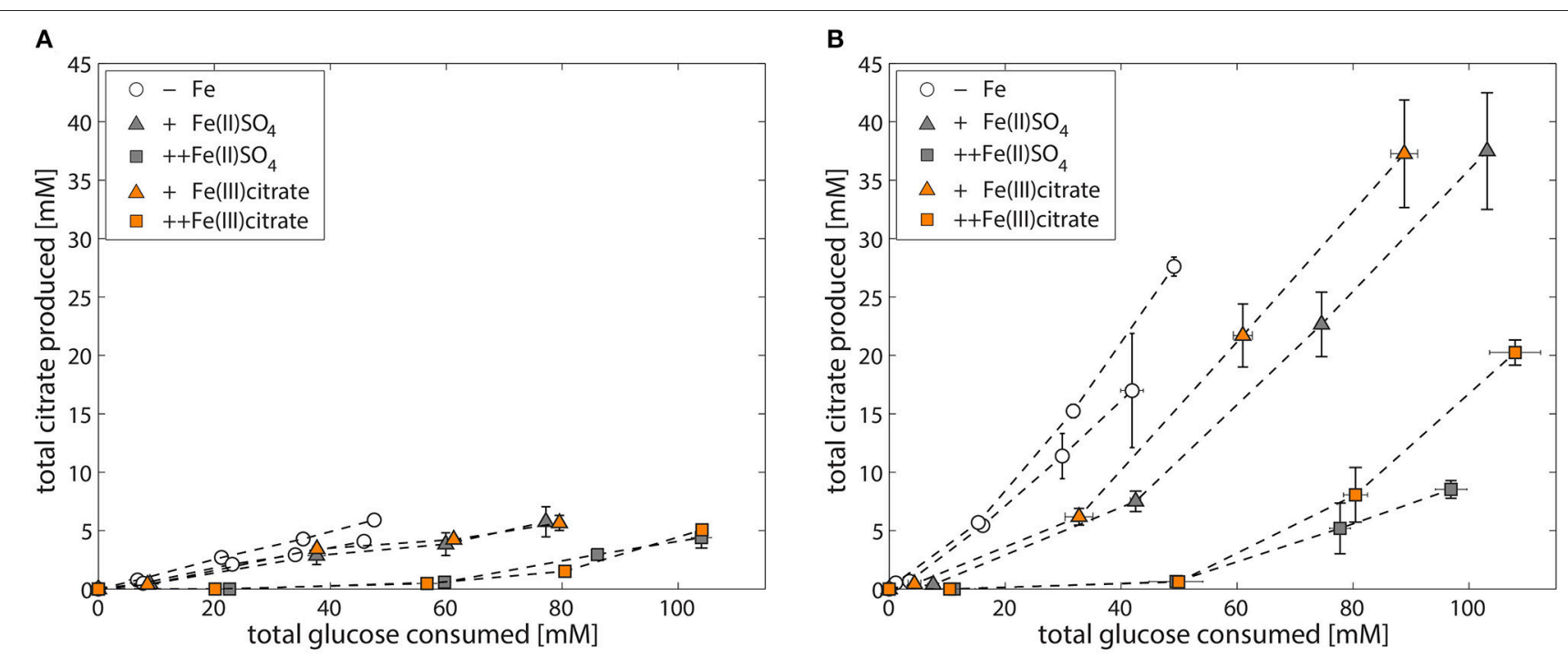

FIGURE 6 | Iron-dependent citrate production of $A$. niger NW305 and NW186 ( N source $\left.=\left(\mathrm{NH}_{4}\right)_{2} \mathrm{SO}_{4}\right)$. Total citrate production per glucose consumption of $A$. niger strains NW305 (A) and NW186 (B), grown without addition of iron (empty circles), or varying amounts of iron (triangles = iron limited, squares = iron excess), added either as $\mathrm{Fe}(\mathrm{II}) \mathrm{SO}_{4}$ (gray, filled symbols) or Fe(III) citrate (orange, filled symbols).

secretion by NW305 - Fe is preceded by intracellular citrate accumulation. However, it has been shown that inhibition of A. niger aconitase does not affect oxalate production (Kubicek et al., 1988), nor does deletion of ATP-citrate lyase (Acl, Figure 1) (Meijer et al., 2009). In contrast, both of these modifications affect $A$. niger citrate production (Kubicek et al., 1988; Meijer et al., 2009). The contrasting effects of these modifications on citrate and oxalate production suggest that it is unlikely that a substantial amount of oxalate is derived from citrate as precursor, which is also in agreement with (Kubicek et al., 1988). Hypothesis (i) is thus inconsistent with the observed A. niger phenotypes (Figures 2, 3).

In the context of the discussion whether inhibition of TCA enzymes downstream of citrate is required for extracellular $A$. niger citrate accumulation, it is noteworthy to mention the aconitase iron-dependency (La Nauze, 1966; Kubicek and Röhr, 1977, 1978; Meixner-Monori et al., 1985; Szczodrak and Ilczuk, 1985). Aconitase catalyzes the conversion of citrate to isocitrate via cis-aconitate. Aconitase inhibition due to lack of iron cofactor would explain the observed increase in citrate secretion upon iron limitation. In addition, it has been shown that aconitase, as well as other iron-dependent enzymes, is subject to HapX repression in A. nidulans (Hortschansky et al., 2007). However, A. niger aconitase, and other TCA cycle enzymes downstream of citrate, have been found to be active during citrate production, even when iron is not added to the medium ( $\mathrm{La}$ Nauze, 1966; Kubicek and Röhr, 1985; Szczodrak and Ilczuk, 1985; Karaffa and Kubicek, 2003).

According to hypothesis (ii) citrate is taking over the biological role of oxalate to increase bioavailability of iron. This hypothesis seems plausible, given that both oxalate and citrate have iron chelating properties (Gadd, 1999). We found that, similarly to iron siderophore biosynthesis pathways (Figure 5) leading to the $A$. niger iron siderophores coprogen $B$ and ferrichrome (Franken et al., 2014), low iron stress is reflected in up-regulation of citrate and oxalate biosynthesis genes citA and oahA, respectively (Table 3, Figure 7).

The role of CitA during citrate production has led to some controversy. CitA catalyzes the condensation of acetyl-CoA with oxaloacetate to form citrate and coenzyme A, and has been shown to have peak activity during A. niger citrate production (Kubicek and Röhr, 1977). However, up to 11-fold overproduction of CitA did not lead to the expected increase in A. niger citrate production (Ruijter et al., 2000). As a response to this work, this was later attributed to the activity of CitA within unmodified cells already being well above the activity which would account for the observed rate of $A$. niger citrate production (Ratledge, 2000; Ratledge and Ruijter, 2000). In another instance, the two mitochondrial citrate synthases in A. niger H915-1 were even found to be down-regulated during the citrate production phase (Yin et al., 2017).

In agreement with (Ratledge, 2000; Ratledge and Ruijter, 2000; Ruijter et al., 2000; Yin et al., 2017), we found that the difference in extracellular citrate accumulation was remarkably independent of citA expression; the gene was not differentially expressed between NW186 - Fe and NW305 - Fe (Table 3, Figure 7). Most remarkably, though, citA was overexpressed in both NW186 - Fe and NW305 - Fe compared to NW305 $++\mathrm{Fe}$, while citrate metabolizing enzymes aconitase (EC 4.2.1.3) and NADP-IDH (EC 1.1.1.42) did not show iron-dependent transcriptional regulation (Table 3, Figure 7). Taken together, these observations suggest that citrate biosynthesis is actively up-regulated in response to iron limitation, but that there is another step of control determining whether citrate is ultimately metabolized (in the case of NW305-Fe), or secreted (in the case of NW186-Fe). 


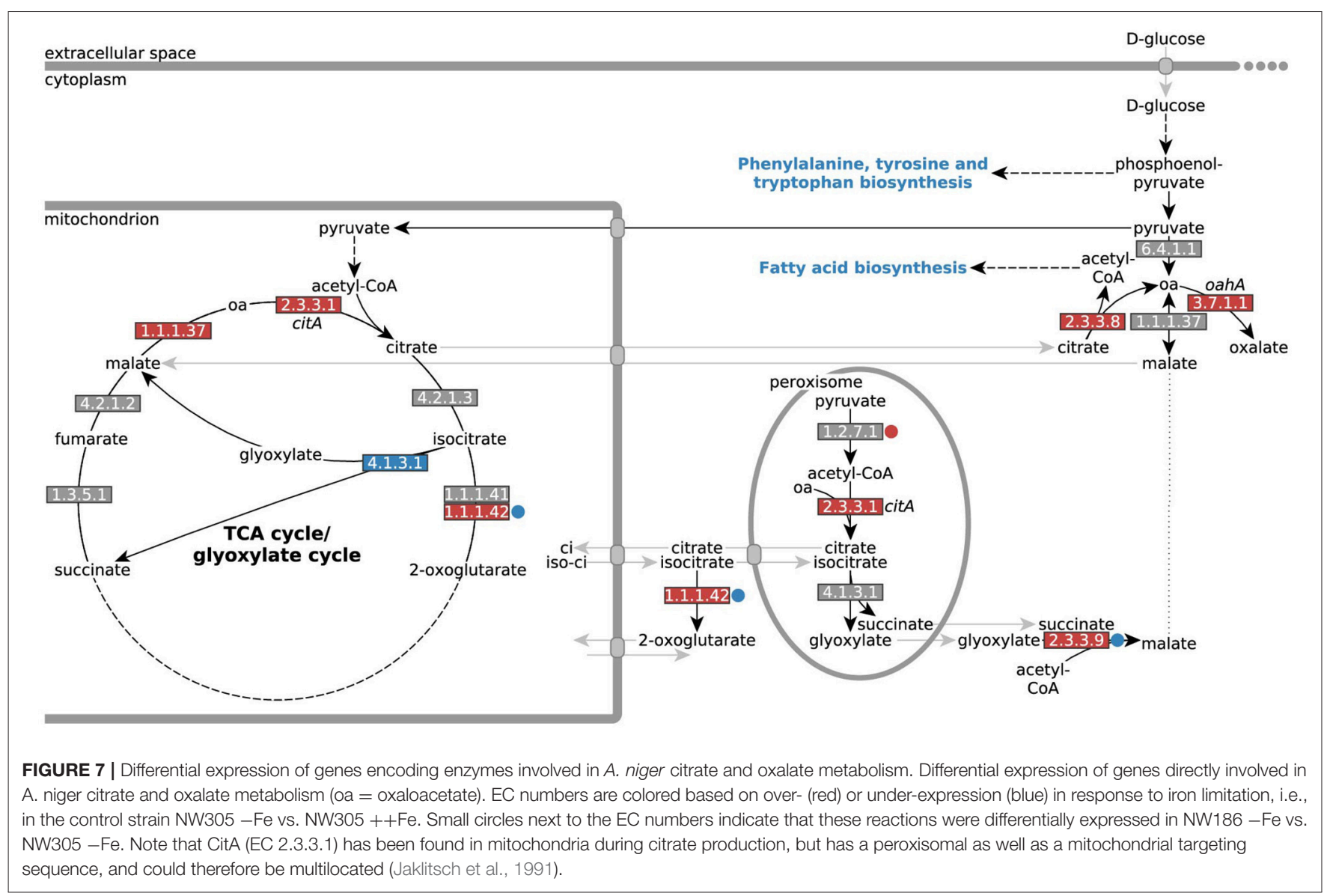

Organelle specific differential expression analysis shows the biggest differences in expression levels of plasma membrane proteins between all 3 conditions (Table 4 ). Therefore, it is likely that extracellular citrate accumulation is ultimately controlled at the transporter level. Transport of citrate was previously hypothesized to be the bottleneck of $A$. niger citrate production (Karaffa and Kubicek, 2003). In our case, we suggest that citrate is only secreted when there is a need to, i.e., in an attempt to increase iron availability under iron limited conditions, and when oxalate is not available for this purpose. Controlling the secretion of citrate irrespective of intracellular citrate biosynthesis, but rather based on the need to increase bioavailability of iron, offers another explanation why overexpression of citA does not, per se, lead to increased extracellular citrate accumulation (Ruijter et al., 2000). Note that the A. niger citrate exporter has, to date, not been identified, but that a list of citrate transporter candidates is provided by Yin et al. (2017).

\section{Fe(III) Citrate as Iron Source for A. niger and Yeast-Type Fungi}

The Fe(III) citrate stability constant of 11.85 [expressed as log (Furia, 2006)], although low in comparison to other microbial iron siderophores (Neilands, 1981), suggests that little metal is released from the complex, even at a low $\mathrm{pH}$. Thus, if $A$. niger lacks the means to deal with iron as metal ion complex with citrate, citrate secretion under low iron stress would effectively lead to an even more drastic iron shortage for the fungus. However, addition of $\mathrm{Fe}(\mathrm{III})$ citrate to $A$. niger culture medium restores the growth phenotype (Table 5, Figure 6), implying that, even if citrate is not employed as endogenous A. niger iron siderophore, the fungus has a means to deal with citrate bound iron as iron source.

Utilization of $\mathrm{Fe}(\mathrm{III})$ citrate as exogenous iron siderophore complex has been shown to take place in various other microbes that do not naturally secrete citrate (Frost and Rosenberg, 1973), and of the yeasts we tested, only C. jadinii was unable to grow when $\mathrm{Fe}(\mathrm{III})$ citrate was added to the medium, although it grew well with $\mathrm{Fe}(\mathrm{II}) \mathrm{SO}_{4}$, and even when no iron was added to the medium. Active citrate uptake in the asexual state of $C$. jadinii (Candida utilis) has been shown to be subject to glucose repression (Cassio and Leao, 1991), and it could be that the utilization of glucose in our experiments prevented C. jadinii from being able to utilize the $\mathrm{Fe}$ (III) citrate complex, whereas it is able to grow on other $\mathrm{Fe}$ (III) salts, such as $\mathrm{Fe}(\mathrm{III}) \mathrm{Cl}_{3}$ (Thomas and Dawson, 1978). This would imply that $C$. jadinii is not able to deal with $\mathrm{Fe}(\mathrm{III})$ citrate via RIA, which is in contrast to $S$. cerevisiae (Haas, 2014). A. niger utilization of the Fe(III) citrate complex did not appear to be subject to glucose repression (Table 5, Figure 6), although measurable uptake of citrate in NW186 is only observed after glucose in the medium is depleted (Supplementary File 1). 
The difference between uptake systems when citrate is utilized as carbon source, or complexed citrate as iron source, appears thus to be a critical aspect that warrants further investigation, but is beyond the scope of this study.

From the data presented, we cannot distinguish whether A. niger employs RIA or imports the entire Fe(III) citrate complex. We found a number of putative "metalloreductases with ferric-chelate reductase activity" (Supplementary File 5), but these could be specific for citrate or any of the other $A$. niger iron siderophores. However, A. niger citrate uptake was studied by Netik et al., who showed that, while citrate export is increased under $\mathrm{Mn}^{2+}$ limited conditions, import of citrate only happens when $\mathrm{Mn}^{2+}$ is present in the medium (Netik et al., 1997). Uptake of citrate was inhibited by EDTA, and Netik et al. hypothesized that EDTA competes for the $\mathrm{Mn}^{2+}$ ions. They conclude that the citrate uptake system in $A$. niger either depends on $\mathrm{Mn}^{2+}$ symport, or, more likely, requires the metal ion chelated form of citrate as a substrate. The requirement of $\mathrm{Mn}^{2+}$ ions for citrate import could be partially replaced by $\mathrm{Mg}^{2+}, \mathrm{Fe}^{2+}$, or $\mathrm{Zn}^{2+}$ (but not $\mathrm{Cu}^{2+}$ ) ions (Netik et al., 1997), indicating that the $A$. niger citrate uptake system is not necessarily restricted to the citrate- $\mathrm{Mn}^{2+}$ complex, but could have a broader specificity for general citrate-metal ion complexes. It is therefore likely that iron is imported as $\mathrm{Fe}$ (III) citrate complex, although further experimental evidence would be required to establish citrate as definite A. niger iron siderophore, especially in the absence of a definitively identified uptake transporter, and bearing in mind that there are other $A$. niger iron siderophores, of which only two have been identified thus far (Franken et al., 2014). Furthermore, the ability of citrate to chelate other metal ions besides iron, and the fact that citrate import had a broad specificity for general citrate-metal-ion complexes (Netik et al., 1997), could imply that A. niger citrate secretion is a more general mechanism to facilitate the uptake of metal ions.

\section{Iron and the $\mathrm{pH}$-Dependency of $\boldsymbol{A}$. niger Organic Acid Production}

When not working with $A$. niger mutants tailored for citrate production, such as NW186, pH control is crucial to inhibit gluconate and oxalate production and enforce production of citrate instead (Ruijter et al., 1999). Certain aspects of the link between external $\mathrm{pH}$ and $A$. niger organic acid production have been elucidated on a molecular level. Glucose oxidase, the enzyme catalyzing the first reaction in the conversion of D-glucose to gluconate, has been shown to be stable only at pH 4-6 (Pazur and Kleppe, 1964), thus explaining the absence of gluconate at lower $\mathrm{pH}$ (Figure 1). The lack of oxalate at lower $\mathrm{pH}$ levels, on the other hand, can be explained by the finding that when the culture medium is below $\mathrm{pH} 2.5$, oxalate decarboxylase, the enzyme that degrades oxalate to $\mathrm{CO}_{2}$ and formate (Figure 1), is synthesized (Emiliani and Bekes, 1964). In a systems level approach, Andersen et al. formulated the hypothesis that the sequential production of organic acids by $A$. niger, and specifically oxalate and citrate, leads to the most efficient acidification of the medium based on the external pH (Andersen et al., 2009). As stated by the authors, continuous acidification of the environment provides a means to effectively outcompete other organisms that are not able to thrive at a low $\mathrm{pH}$, thereby providing an evolutionary advantage for the fungus (Andersen et al., 2009).

In this study, we worked with $A$. niger mutants that are incapable of producing either gluconate or both gluconate and oxalate. Therefore, it was not necessary to exert control over external culture $\mathrm{pH}$ to enforce citrate production. In almost all the $A$. niger strains and conditions tested, the biggest $\mathrm{pH}$ drop (to $\sim \mathrm{pH} 2-4$, Supplementary File 7 ) was observed after $24 \mathrm{~h}$ of growth. The $\mathrm{pH}$ continued to decrease steadily after that, albeit at a slower pace. This pattern is broken when iron is added to NW186 pre-grown without iron (Figure 2B, Supplementary File 1), or when glucose is depleted (Supplementary File 1). In both cases, the $\mathrm{pH}$ stops dropping and appears to even rise again (Supplementary Figures 2B, 3B in Supplementary File 1). This is likely due to consumption of citrate in the glucose depleted cultures, but it is not clear what the fungus is taking back up in the case of the iron pulse. Although it is tempting to link the rising $\mathrm{pH}$ to the net uptake of an iron-citrate complex, it is also possible that the $\mathrm{pH}$ rises due to an increased activity of $\mathrm{H}^{+}$symport of another iron-siderophore or compound.

A general observation in fungi is that organic acid secretion is actually higher at higher external $\mathrm{pH}$, and that there is a continuous influx and efflux of organic acids (Vrabl et al., 2012). Besides the discussed hypothesis that acidification of the medium might serve to outcompete other organisms, acidification of the environment is also a means of increasing iron solubility and thus bioavailability (Dutton and Evans, 1996; Gadd, 1999). Based on the results presented and discussed, we propose that citrate, and possibly also oxalate and gluconate, are not just secreted to acidify the medium, but that the sequential secretion of gluconate, oxalate, and then citrate is based on optimally increasing bioavailability of iron based on their own chelating properties at the given external $\mathrm{pH}$, and as such serve as $A$. niger iron siderophores. The fact that oxalate secretion precedes citrate secretion until $\mathrm{pH} \leq 2.5$ can be associated to the lower stability constant of the Fe(III) oxalate complex compared to the Fe(III) citrate complex [9.4 compared to 11.85 (Furia, 2006)], implying that the $\mathrm{Fe}$ (III) citrate complex is more stable at lower $\mathrm{pH}$ values.

The increased correlation between iron limitation and citrate production observed in the exclusively citrate producing $A$. niger mutant $\mathrm{NW} 186$, even at a $\mathrm{pH}$ that would usually be considered suboptimal for citrate production (Ruijter et al., 1999), is due to citrate being the only organic acid available for a task that would otherwise be shared between, and optimally adjusted to, multiple organic acids. The dependency of $A$. niger organic acid production on ambient $\mathrm{pH}$ also draws parallels to iron siderophore metabolism in Aspergillus nidulans, where, consistent with the insolubility of iron at alkaline $\mathrm{pH}$, production of $A$. nidulans iron siderophores increases with an increase in culture pH (Eisendle et al., 2004).

Based on these insights, our findings, and in line with the observation that $A$. niger imports citrate only as metalion complex (Netik et al., 1997), we suggests that increased 
citrate secretion under iron limited conditions is a physiological response to, rather than just a consequence of, low iron availability. Specifically, we propose that the reason $A$. niger citrate synthesis is actively up-regulated under iron limited conditions is because the fungus employs citrate as iron siderophore.

\section{AUTHOR CONTRIBUTIONS}

DO, TS, VM, MS, and PS conceived and designed the work. MG and TS performed the experiments. DO, TS, and MS analyzed the data. DO, MG, TS, JT, MS, and PS contributed to the interpretation of the data. DO wrote the manuscript, and MS and PS participated therein. DO, MG, TS, JT, VM, MS, and PS critically revised the manuscript for intellectual content. All authors have read and agree to the submission of the manuscript.

\section{REFERENCES}

Andersen, M. R., Lehmann, L., and Nielsen, J. (2009). Systemic analysis of the response of Aspergillus niger to ambient pH. Genome Biol. 10:R47. doi: 10.1186/gb-2009-10-5-r47

Andersen, M. R., Salazar, M. P., Schaap, P. J., Van De Vondervoort, P. J. I., Culley, D., Thykaer, J., et al. (2011). Comparative genomics of citric-acid-producing Aspergillus niger ATCC 1015 versus enzyme-producing CBS 513.88. Genome Res. 21, 885-897. doi: 10.1101/gr.112169.110

Blatzer, M., Barker, B. M., Willger, S. D., Beckmann, N., Blosser, S. J., Cornish, E. J., et al. (2011). SREBP coordinates iron and ergosterol homeostasis to mediate triazole drug and hypoxia responses in the human fungal pathogen Aspergillus fumigatus. PLoS Genet. 7:e1002374. doi: 10.1371/journal.pgen.1002374

Bolger, A. M., Lohse, M., and Usadel, B. (2014). Trimmomatic: a flexible trimmer for Illumina sequence data. Bioinformatics 30, 2114-2120. doi: 10.1093/bioinformatics/btu170

Cassio, F., and Leao, C. (1991). Low- and high-affinity transport systems for citric acid in the yeast Candida utilis. Appl. Environ. Microbiol. 57, 3623-3628.

Chesters, C. G., and Rolinson, G. N. (1951). Zinc in the metabolism of a strain of Aspergillus niger. J. Gen. Microbiol. 5, 553-558. doi: 10.1099/00221287-5-3-553

Claudel-Renard, C., Chevalet, C., Faraut, T., and Kahn, D. (2003). Enzyme-specific profiles for genome annotation: PRIAM. Nucleic Acids Res. 31, 6633-6639. doi: 10.1093/nar/gkg847

Cox, C. D. (1980). Iron uptake with ferripyochelin and ferric citrate by Pseudomonas aeruginosa. J. Bacteriol. 142, 581-587.

Cox, G. B., Gibson, F., Luke, R. K., Newton, N. A., O’Brien, I. G., and Rosenberg, H. (1970). Mutations affecting iron transport in Escherichia coli. J. Bacteriol. 104, 219-226.

Currie, J. N. (1917). The citric acid fermentation of Aspergillus niger. J. Biol. Chem. 31, 15-37.

Dobin, A., Davis, C. A., Schlesinger, F., Drenkow, J., Zaleski, C., Jha, S., et al. (2013). STAR: ultrafast universal RNA-seq aligner. Bioinformatics 29, 15-21. doi: 10.1093/bioinformatics/bts635

Dutton, M. V., and Evans, C. S. (1996). Oxalate production by fungi: its role in pathogenicity and ecology in the soil environment. Can. J. Microbiol. 42, 881-895. doi: 10.1139/m96-114

Eisendle, M., Oberegger, H., Buttinger, R., Illmer, P., and Haas, H. (2004). Biosynthesis and uptake of siderophores is controlled by the PacC-mediated ambient-pH regulatory system in Aspergillus nidulans. Eukaryotic Cell 3, 561-563. doi: 10.1128/EC.3.2.561-563.2004

Emiliani, E., and Bekes, P. (1964). Enzymatic oxalate decarboxylation in Aspergillus niger. Arch. Biochem. Biophys. 105, 488-493. doi: 10.1016/0003-9861(64)90040-2

\section{FUNDING}

WUR IPOP Systems Biology program KB-17-003.02-026 "Genome-wide metabolic modeling and data integration of organic acid production in filamentous fungi."

\section{ACKNOWLEDGMENTS}

We want to thank Alex Kruis for interesting and fruitful discussions, Ruben van Heck for reading and commenting on the manuscript, and Wen Wu for help and feedback on the figures.

\section{SUPPLEMENTARY MATERIAL}

The Supplementary Material for this article can be found online at: http://journal.frontiersin.org/article/10.3389/fmicb. 2017.01424/full\#supplementary-material

Franken, A. C. W., Lechner, B. E., Werner, E. R., Haas, H., Lokman, B. C., Ram, A. F. J., et al. (2014). Genome mining and functional genomics for siderophore production in Aspergillus niger. Brief. Funct. Genomics 13, 482-492. doi: 10.1093/bfgp/elu026

Frost, G. E., and Rosenberg, H. (1973). The inducible citrate-dependent iron transport system in Escherichia coli K12. Elsevier 330, 90-101. doi: 10.1016/0005-2736(73)90287-3

Furia, T. E. (2006). "Stability Constants (log K1) of Various Metal Chelates," in Sequestrants in Foods, 2. Available online at: http://www.coldcure.com/html/stability_constants.html

Gadd, G. M. (1999). Fungal production of citric and oxalic acid: importance in metal speciation, physiology and biogeochemical processes. Adv. Microb. Physiol. 41, 47-92. doi: 10.1016/S0065-2911(08)60165-4

Goosen, T., van Engelenburg, F., Debets, F., Swart, K., Bos, K., and van den Broek, H. (1989). Tryptophan auxotrophic mutants in Aspergillus niger: inactivation of the trpC gene by cotransformation mutagenesis. Mol. Gen. Genet. 219, 282-288. doi: 10.1007/BF00261189

Gründlinger, M., Yasmin, S., Lechner, B. E., Geley, S., Schrettl, M., Hynes, M., et al. (2013). Fungal siderophore biosynthesis is partially localized in peroxisomes. Mol. Microbiol. 88, 862-875. doi: 10.1111/mmi.12225

Guerinot, M. L., and Yi, Y. (1994). Iron: nutritious, noxious, and not readily available. Plant Physiol. 104, 815-820. doi: 10.1104/pp.104.3.815

Guerinot, M. L., Meidl, E. J., and Plessner, O. (1990). Citrate as a Siderophore in Bradyrhizobium japonicum. J. Bacteriol. 172, 3298-3303. doi: 10.1128/jb.172.6.3298-3303.1990

Haas, H. (2003). Molecular genetics of fungal siderophore biosynthesis and uptake: the role of siderophores in iron uptake and storage. Appl. Microbiol. Biotechnol. 62, 316-330. doi: 10.1007/s00253-003-1335-2

Haas, H. (2012). Iron - a key nexus in the virulence of Aspergillus fumigatus. Front. Microbiol. 3:28. doi: 10.3389/fmicb.2012.00028

Haas, H. (2014). Fungal siderophore metabolism with a focus on Aspergillus fumigatus. Nat. Prod. Rep. 31, 1266-1276. doi: 10.1039/C4NP $00071 \mathrm{D}$

Han, Y., Joosten, H. J., Niu, W., Zhao, Z., Mariano, P. S., McCalman, M., et al. (2007). Oxaloacetate hydrolase, the $\mathrm{C}-\mathrm{C}$ bond lyase of oxalate secreting fungi. J. Biol. Chem. 282, 9581-9590. doi: 10.1074/jbc.M608961200

Hortschansky, P., Eisendle, M., Al-Abdallah, Q., Schmidt, A. D., Bergmann, S., Thön, M., et al. (2007). Interaction of HapX with the CCAAT-binding complex-a novel mechanism of gene regulation by iron. EMBO J. 26, 3157-3168. doi: 10.1038/sj.emboj.7601752

Jaklitsch, W. M., Kubicek, C. P., and Scrutton, M. C. (1991). Intracellular location of enzymes involved in citrate production by Aspergillus niger. Can. J. Microbiol. 37, 823-827. doi: 10.1139/m91-142 
Kanehisa, M., and Goto, S. (2000). KEGG: kyoto encyclopedia of genes and genomes. Nucleic Acids Res. 28, 27-30. doi: 10.1093/nar/28.1.27

Kanehisa, M., Sato, Y., Kawashima, M., Furumichi, M., and Tanabe, M. (2015). KEGG as a reference resource for gene and protein annotation. Nucleic Acids Res. 44, D457-D462. doi: 10.1093/nar/ gkv1070

Karaffa, L., and Kubicek, C. P. (2003). Aspergillus niger citric acid accumulation: do we understand this well working black box? Appl. Microbiol. Biotechnol. 61, 189-196. doi: 10.1007/s00253-002-1201-7

Kopylova, E., Noé, L., and Touzet, H. (2012). SortMeRNA: fast and accurate filtering of ribosomal RNAs in metatranscriptomic data. Bioinformatics 28, 3211-3217. doi: 10.1093/bioinformatics/bts611

Kubicek, C. P., and Röhr, M. (1977). Influence of manganese on enzyme synthesis and citric acid accumulation in Aspergillus niger. Eur. J. Appl. Microbiol. 4, 167-175. doi: 10.1007/BF01390476

Kubicek, C. P., and Röhr, M. (1978). The role of the tricarboxylic acid cycle in citric acid accumulation by Aspergillus niger. Eur. J. Appl. Microbiol. Biotechnol. 5, 263-271. doi: 10.1007/BF00504714

Kubicek, C. P., and Röhr, M. (1985). Aconitase and citric acid fermentation by Aspergillus niger. Appl. Environ. Microbiol. 50, 1336-1338.

Kubicek, C. P., Schreferl-Kunar, G., Wöhrer, W., and Röhr, M. (1988). Evidence for a cytoplasmic pathway of oxalate biosynthesis in Aspergillus niger. Appl. Environ. Microbiol. 54, 633-637.

Kusters-van Someren, M. A., Harmsen, J. A., Kester, H. C., and Visser, J. (1991). Structure of the Aspergillus niger pelA gene and its expression in Aspergillus niger and Aspergillus nidulans. Curr. Genet. 20, 293-299. doi: $10.1007 /$ BF00318518

La Nauze, J. M. (1966). Aconitase and isocitric dehydrogenases of Aspergillus niger in relation to citric acid production. J. Gen. Microbiol. 44, 73-81. doi: 10.1099/00221287-44-1-73

Meijer, S., Nielsen, M. L., Olsson, L., and Nielsen, J. (2009). Gene deletion of cytosolic ATP:citrate lyase leads to altered organic acid production in Aspergillus niger. J. Ind. Microbiol. Biotechnol. 36, 1275-1280. doi: 10.1007/s10295-009-0607-y

Meixner-Monori, B., Kubicek, C. P., Habison, A., Kubicek-Pranz, E. M., and Röhr, M. (1985). Presence and regulation of the alpha-ketoglutarate dehydrogenase multienzyme complex in the filamentous fungus Aspergillus niger. J. Bacteriol. $161,265-271$.

Neilands, J. B. (1981). Microbial iron compounds. Annu. Rev. Biochem. 50, 715-730. doi: 10.1146/annurev.bi.50.070181.003435

Neilands, J. B. (1995). Siderophores: structure and function of microbial iron transport compounds. J. Biol. Chem. 270, 26723-26726. doi: $10.1074 /$ jbc.270.45.26723

Netik, A., Torres, N. V., Riol, J. M., and Kubicek, C. P. (1997). Uptake and export of citric acid by Aspergillus niger is reciprocally regulated by manganese ions. Biochim. Biophys. Acta Biomembr. 1326, 287-294. doi: 10.1016/S0005-2736(97)00032-1

Nordberg, H., Cantor, M., Dusheyko, S., Hua, S., Poliakov, A., Shabalov, I., et al. (2014). The genome portal of the department of energy joint genome institute: 2014 updates. Nucleic Acids Res. 42, D26-D31. doi: 10.1093/nar/ gkt1069

Pazur, J. H., and Kleppe, K. (1964). The oxidation of glucose and related compounds by glucose oxidase from Aspergillus niger. Biochemsitry 3, 578-583. doi: 10.1021/bi00892a018

Quinlan, A. R., and Hall, I. M. (2010). BEDTools: a flexible suite of utilities for comparing genomic features. Bioinformatics 26, 841-842. doi: 10.1093/bioinformatics/btq,033

R Core, T. (2014). R: A Language and Environment for Statistical Computing. Available online at: http://www.r-project.org/

Ratledge, C. (2000). Look before you clone. FEMS Microbiol. Lett. 189, 317-318. doi: 10.1111/j.1574-6968.2000.tb09250.x

Ratledge, C., and Ruijter, G. J. G. (2000). Life is not that simple. FEMS Microbiol. Lett. 189, 317-318.
Robinson, M. D., McCarthy, D. J., and Smyth, G. K. (2009). edgeR: a Bioconductor package for differential expression analysis of digital gene expression data. Bioinformatics 26, 139-140. doi: 10.1093/bioinformatics/ btp616

Ruijter, G. J. G., Bax, M., Patel, H., Flitter, S. J., Van De Vondervoort, P. J. I., De Vries, R. P., et al. (2003). Mannitol is required for stress tolerance in Aspergillus niger conidiospores. Eukaryotic Cell 2, 690-698. doi: 10.1128/EC.2.4.690-698.2003

Ruijter, G. J. G., Panneman, H., and Visser, J. (1997). Overexpression of phosphofructokinase and pyruvate kinase in citric acid-producing Aspergillus niger. Biochim. Biophys. Acta Gen. Subj. 1334, 317-326. doi: 10.1016/S0304-4165(96)00110-9

Ruijter, G. J. G., Panneman, H., Xu, D. B., and Visser, J. (2000). Properties of Aspergillus niger citrate synthase and effects of citA overexpression on citric acid production. FEMS Microbiol. Lett. 184, 35-40. doi: 10.1111/j.1574-6968.2000.tb08986.x

Ruijter, G. J. G., Van De Vondervoort, P. J. I., and Visser, J. (1999). Oxalic acid production by Aspergillus niger: an oxalate-non-producing mutant produces citric acid at $\mathrm{pH} 5$ and in the presence of manganese. Microbiology 145, 2569-2576. doi: 10.1099/00221287-145-9-2569

Schomburg, I., Chang, A., Ebeling, C., Gremse, M., Heldt, C., Huhn, G., et al. (2004). BRENDA, the enzyme database: updates and major new developments. Nucleic Acids Res. 32, D431-D433. doi: 10.1093/nar/gkh081

Schrader, M., and Fahimi, H. D. (2006). Peroxisomes and oxidative stress. Biochim. Biophys. Acta Mol. Cell Res. 1763, 1755-1766. doi: 10.1016/j.bbamcr.2006.09.006

Schrettl, M., Kim, H. S., Eisendle, M., Kragl, C., Nierman, W. C., Heinekamp, T., et al. (2008). SreA-mediated iron regulation in Aspergillus fumigatus. Mol. Microbiol. 70, 27-43. doi: 10.1111/j.1365-2958.2008.06376.x

Schuster, E., Dunn-Coleman, N., Frisvad, J., and Van Dijck, P. (2002). On the safety of Aspergillus niger A review. Appl. Microbiol. Biotechnol. 59, 426-435. doi: 10.1007/s00253-002-1032-6

Silva, A. M. N., Kong, X., Parkin, M. C., Cammack, R., and Hider, R. C. (2009). Iron(III) citrate speciation in aqueous solution. Dalton Trans. 8616-8625. doi: 10.1039/b910970f

Szczodrak, J., and Ilczuk, Z. (1985). Effect of iron on the activity of aconitate hydratase and synthesis of citric acid by Aspergillus niger. Zentralbl. Mikrobiol. 140, 567-574.

Thomas, K. C., and Dawson, P. S. S. (1978). Relationship between iron-limited growth and energy limitation during phased cultivation of Candida utilis. Can. J. Microbiol. 24, 440-447. doi: 10.1139/m78-073

Verduyn, C., Postma, E., Scheffers, W. A., and Van Dijken, J. P. (1992). Effect of benzoic acid on metabolic fluxes in yeasts: a continuous-culture study on the regulation of respiration and alcoholic fermentation. Yeast 8, 501-517. doi: $10.1002 /$ yea. 320080703

Vishniac, W., and Santer, M. (1957). The Thiobacilli. Bacteriol. Rev. 21, 195-213.

Vrabl, P., Fuchs, V., Pichler, B., Schinagl, C. W., and Burgstaller, W. (2012). Organic acid excretion in Penicillium ochrochloron increases with ambient $\mathrm{pH}$. Front. Microbiol. 3:121. doi: 10.3389/fmicb.2012.00121

Yin, X., Shin, H.-D., Li, J., Du, G., Liu, L., and Chen, J. (2017). Comparative genomics and transcriptome analysis of Aspergillus niger and metabolic engineering for citrate production. Sci. Rep. 7:41040. doi: 10.1038/srep41040

Conflict of Interest Statement: The authors declare that the research was conducted in the absence of any commercial or financial relationships that could be construed as a potential conflict of interest.

Copyright (c) 2017 Odoni, van Gaal, Schonewille, Tamayo-Ramos, Martins dos Santos, Suarez-Diez and Schaap. This is an open-access article distributed under the terms of the Creative Commons Attribution License (CC BY). The use, distribution or reproduction in other forums is permitted, provided the original author(s) or licensor are credited and that the original publication in this journal is cited, in accordance with accepted academic practice. No use, distribution or reproduction is permitted which does not comply with these terms. 